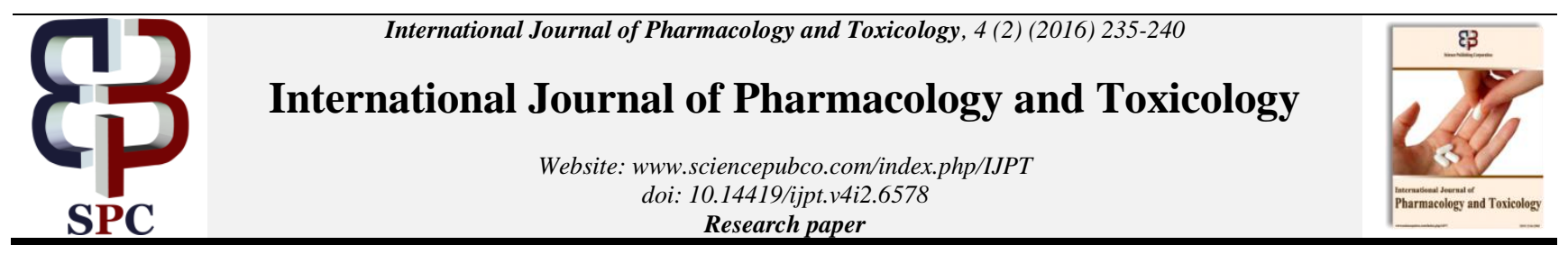

\title{
Free radical scavenging activity of aqueous and alcoholic extracts of Glycyrrhiza glabra Linn. measured by ferric reducing antioxidant power (FRAP), ABTS bleaching assay ( $\alpha$ TEAC), DPPH assay and peroxyl radical antioxidant assay
}

\author{
Mradu Gupta ${ }^{1 *}$, Nandita Karmakar ${ }^{2}$, Saswati Sasmal ${ }^{2}$, Saikat Chowdhury ${ }^{2}$, Suman Biswas ${ }^{2}$ \\ ${ }^{1}$ Professor \& Head, Department of Dravyaguna (Medicinal Plant Pharmacology), Institute of Post Graduate \\ Ayurvedic Education and Research, 294 /3/ 1, A. P. C. Road, Kolkata, India - 700009 \\ ${ }^{2}$ Institute of Post Graduate Ayurvedic Education and Research, 294/3/1, A. P. C. Road, Kolkata, India - 700009 \\ *Corresponding author E-mail: mradu_gupta@hotmail.com
}

\begin{abstract}
The present study evaluates the in vitro antioxidant free radical scavenging capacities of aqueous and alcoholic extracts of Glycyrrhiza glabra since this medicinal plant has been traditionally used in Ayurvedic system of medicine as a tonic, rejuvenator, demulcent and expectorant. Total phenolic content of alcoholic extract and aqueous extract was found as 18.70 and 23.26 Gallic acid equivalents/mg while the total flavonoid content was assessed as 15.03 and 6.62 Quercetin equivalents $/ \mathrm{mg}$ respectively. $\mathrm{IC} 50(\mu \mathrm{g} / \mathrm{ml})$ of alcoholic, aqueous extract and Ascorbic acid was found to be 65.064 $\pm 3.538,73.423 \pm 9.057$ and 18.156 \pm 1.356 in Hydrogen Peroxide Radical Scavenging, $1.424 \pm 0.013$ $1.632 \pm 0.052$ and $0.879 \pm 0.273$ in DPPH radical scavenging, and 335.948 $\pm 29.040,251.891 \pm 6.330$ and $6.142 \pm 0.061$ during FRAP essay. Similarly, during ABTS radical scavenging, $\mathrm{IC}_{50}(\mu \mathrm{g} / \mathrm{ml})$ was assessed as $575 \pm 26.694,683.9 \pm 49.220$ and $6.337 \pm 0.167$ for alcoholic, aqueous extract and Trolox respectively. While both the extracts showed substantial and significant free radical scavenging activity during the study which is compared to that of standard drug, the alcoholic extract of Glycyrrhiza glabra exhibits higher in vitro antioxidant activity than the aqueous extract in all assessment methods except FRAP, possibly due to higher concentrations of flavonoids in it, validating and confirming the therapeutic properties ascribed to it in Ayurvedic texts.
\end{abstract}

Keywords: ABTS; Antioxidant Capacity; DPPH; FRAP; Glycyrrhiza Glabra.

\section{Introduction}

Antioxidants are molecules that quench free radical reactions and delay or inhibit cellular damage. Though the antioxidant defenses are different from species to species, the presence of the antioxidant defense is universal. Antioxidants exist both in enzymatic and nonenzymatic forms in the intracellular and extracellular environment. Enzymatic antioxidants work by breaking down and removing free radicals. The antioxidant enzymes convert dangerous oxidative products to hydrogen peroxide $\left(\mathrm{H}_{2} \mathrm{O}_{2}\right)$ and then to water, in a multistep process in presence of cofactors such as copper, zinc, manganese, and iron. Non-enzymatic antioxidants work by interrupting free radical chain reactions. Few examples of the non-enzymatic antioxidants are vitamin C, vitamin E, plant polyphenol, carotenoids, and glutathione (Wang \& Jiao 2000, Živković et al. 2010). Glycyrrhiza glabra Linn. also called liquorice root belongs to the Fabaceae family. It is a perineal herb/sub-shrub found in the subtropical and temperate zones. The plant attains a maximum height up to $2 \mathrm{~m}$. The underground stem grows horizontally up to $2 \mathrm{~m}$ length, highly branched consisting of a short tap root with a large number of rhizomes. The diameter of the root varies from 0.75 to $2.5 \mathrm{~cm}$, grey-brown exterior and yellow interior. Externally, it is longitudinally wrinkled with patches of cork. It has a characteristic pleasant sweet taste. Leaves alternate, pinnate, yellow-green leaflets 4-7 pairs are covered with soft hairs on the underside. Flowers appear in an axil of terminal and axillary leaves in raceme, pea-like, lavender to purple in colour. Seed pod is $2-2.5 \mathrm{~cm}$ long containing 2-5 seeds. Flowering \& fruiting is from August to February. Its underground stems and roots are used medicinally for treatment of cough, hyperacidity, skin and ophthalmic diseases and as a tonic, rejuvenator, demulcent, expectorant, etc. The chief constituent of liquorice is Glycyrrhizin, which is present in the drug in the form of the potassium and calcium salts of Glycyrrhizic acid. Glycyrrhizic acid is not a glycoside since it yields on hydrolysis one molecule of Glycyrrhetic acid and two molecules of Glycuronic acid but no sugar. Glycuronic acid is, however, very closely related to the hexose sugars, and Glycyrrhetic acid has a haemolytic action like that of the saponins. Liqourice also contains glucose (up to 3.8 per cent), sucrose ( 2.4 to 6.5 per cent), bitter principles, resins, mannite, asparagines ( 2 to 4 per cent) and fat ( 0.8 per cent). Its pharmacological activities are reported to be muscle depressant, anti-microbial, hypo-lipidemic, anti-antherosclerotic, antiviral, hypotensive, hepato-protective, anti-exudative, spasmolytic, antidiuretic, antiulcer, anti-mutagenic, antipyretic, antioxidant, anti-inflammatory, anti-nociceptive and expectorant (Sharma 1995, Sharma et al. 2001, Kirtikar \& Basu 1989, Baba \& Malik 2015, Harborne 1984). 
During the present study, the aqueous and alcoholic extracts of the roots of Glycyrrhiza glabra were initially assessed for their phenolic and flavonoid contents. Thereafter, they were screened for their antioxidant capacities using in vitro standard procedures namely ferric reducing antioxidant power (FRAP), ABTS bleaching assay $(\alpha \mathrm{TEAC}), \mathrm{DPPH}$ assay and peroxyl radical scavenging assay strategies where plants are generally assessed for their function as reducing agents, hydrogen donors, singlet oxygen quenchers or metal chelators. The objective of the research was to assess the medicinal potential of this formulation, especially its antioxidant potential in the form of free radical scavenging activity, using scientific techniques and thus justify its traditional and folklore use as a substantial and reliable rejuvenator herbal formulation.

\section{Materials and methods}

\subsection{Plant materials}

The roots of Glycyrrhiza glabra Linn. were purchased from crude drug supplier of Katwa Chowrasta, Burdwan district and the plant samples were authenticated by the Research Officer, Botanical Survey of India, Howrah. India vide Ref. No. BSI/CNH/SF/Tech./2016.

\subsection{Chemicals}

Potassium Sodium Tertrate, Aluminium chloride, Folin-Ciocalteu's reagent, sodium carbonate, Sulphuric acid, Hydrogen peroxide, Ferric Chloride (FeCl3), Di-Sodium hydrogen Phosphate and $\mathrm{Bu}-$ tylated hydroxytoluene (BHT) were obtained from Merck Specialties Pvt. Ltd., Mumbai, India. 2, 2- azinobis (three ethyl-benzothiazole-6-sulfonic acid) [ABTS] was obtained from Roche's diagnostics, Mannheim, Germany while 6-hydroxy-2, 5, 7, 8- tetramethyl2-carboxylic acid (Trolox) was obtained from Fluka, Buchs, Switzerland. Quercetin was purchased from Sisco Research Laboratories Pvt. Ltd., Mumbai, India. Gallic acid, Ascorbic acid, Potassium persulphate, Potassium ferricyanide and Trichloro acetic acid were obtained from Nice Chemicals Pvt. Ltd. Kochi, Kerala, India. Sodium phosphate was obtained from Sarabhai M. Chemicals Limited, Shantisadan, Ahmedabad, Gujarat, India and Ammonium molybdate was obtained from GFS chemicals, United States. 1, 1-diphenyl-2-picrylhydrazyl (DPPH) was purchased from MP Biomedicals, France.

\subsection{Preparation of extracts}

The roots of Glycyrrhiza glabra Linn. were washed, sun dried and crushed to particle size of 40 mesh. This coarse powder was sequentially extracted with petroleum ether $\left(60^{\circ} \mathrm{C}-80^{\circ} \mathrm{C}\right)$, chloroform, acetone, ethanol and water using soxhlet apparatus. These extracts were filtered using a Buckner funnel and Whatman No. 1 filter paper at room temperature and concentrated at reduced temperature and pressure using rotary evaporator. All obtained extracts were stored in refrigerator below $10^{\circ} \mathrm{C}$ for subsequent experiments. The aqueous and alcoholic (ethanol) extracts of the roots of Sida cordifolia were used in the study.

\subsection{Total phenol content}

The Folin- Ciocalteu reagent was used for determining the total phenol content. To $0.5 \mathrm{ml}$ aliquot of dried aqueous extract of Glycyrrhiza glabra, $2.5 \mathrm{ml}$ of Folin- Ciocalteu's reagent (10\%) and two ml of $7.5 \%$ sodium carbonate were added. The absorbance was read after $30 \mathrm{~min}$ incubation period at room temperature at $760 \mathrm{~nm}$ colorimetrically. By using 100, 200, 300, 400, and $500 \mu \mathrm{g} / \mathrm{ml}$ concentrations of Gallic acid, a standard calibration plot was generated at $760 \mathrm{~nm}$. The concentrations of phenol in the test samples were calculated from the calibration plot. Total phenolic content was expressed as mg Gallic Acid Equivalents (GAE). All determinations were performed in triplicates, and the results were expressed as $\mathrm{mg}$
Gallic Acid Equivalents per gm sample extract (Baba \& Malik 2015, Harborne 1984).

\subsection{Total flavonoid content}

Total Flavonoid content was determined using the Aluminum chloride $\left[\mathrm{AlCl}_{3}\right]$ method. An aliquot of $0.5 \mathrm{ml}$ of sample $(1 \mathrm{mg} / \mathrm{ml})$ was mixed with $1.5 \mathrm{ml}$ of methanol, $0.1 \mathrm{ml}$ of $1 \%$ aluminum chloride and $0.1 \mathrm{ml}$ of potassium acetate solution $(1 \mathrm{M})$. In the mixture, 2.8 $\mathrm{ml}$ of distilled water was added to bring up the total volume to $5 \mathrm{ml}$. The test solution was shaken vigorously and Absorbance at $415 \mathrm{~nm}$ was recorded after 30 minutes of incubation. A standard calibration plot was generated at $415 \mathrm{~nm}$ using different and known concentrations of Quercetin. The concentrations of flavonoid in the test samples were calculated from the calibration plot and expressed as $\mathrm{mg}$ Quercetin equivalent/gm of sample (Chang et al. 2002, Usha Sri et al. 2012).

\subsection{Hydrogen peroxide radical scavenging}

The ability of the extracts to scavenge hydrogen peroxide was determined according to the method of Keser et al. (2012). A solution of hydrogen peroxide $(40 \mathrm{mM})$ was prepared in phosphate buffer (pH 7.4). Alcoholic and Aqueous extracts (24.94, 49.75 and 74.44 $\mu \mathrm{g} / \mathrm{ml})$ were added to hydrogen peroxide solution $(0.6 \mathrm{ml}, 40 \mathrm{mM})$. Absorbance of hydrogen peroxide at $230 \mathrm{~nm}$ was determined spectrophotometrically by UV-VIS (Shimadzu UV 2450) 10 minutes later against a blank solution containing the phosphate buffer without hydrogen peroxide and compared with ascorbic acid (12.42, $24.69,36.81$ and 48.78 and $74.44 \mu \mathrm{g} / \mathrm{ml}$ ), the reference compound. The percentage of hydrogen peroxide scavenging of extracts and standard compounds were calculated using the methods outlined by Basniwal et al. 2009 and Nishaa et al. 2012.

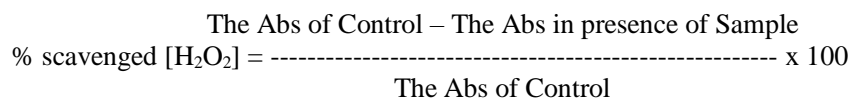

\subsection{DPPH radical scavenging assay}

The DPPH $0.1 \mathrm{mM}$ solution in ethanol was prepared. This solution $(3 \mathrm{ml})$ was added to $1 \mathrm{ml}$. of alcoholic and aqueous extracts at different concentrations $(0.5,1.0 \& 2.0 \mathrm{mg} / \mathrm{ml})$. The mixture was shaken vigorously and allowed to stand at room temp in dark for 30 min. and thereafter the absorbance was measured at $517 \mathrm{~nm}$ by using UV-VIS Shimadzu UV 2450 spectrophotometer (Anil et al. 2011, Özcelik et al. 2003).Ascorbic acid was used as standard due to its strong reducing power and weak metal-chelating ability and used in different concentrations of $0.050,0.100,0.150$ and 0.200 $\mathrm{mg} / \mathrm{ml}$. The IC 50 value of the sample, which is the concentration of sample required to inhibit $50 \%$ of the DPPH free radical, was calculated using inhibition curve. Lower absorbance of the reaction mixture indicated higher free radical activity. Linear graph of concentration vs. percentage inhibition was prepared using various concentrations of Ascorbic acid and $\mathrm{IC}_{50}$ values were calculated. The percent DPPH scavenging effect was calculated by using the following equation:

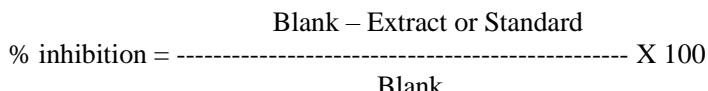

Where Blank was the absorbance of the control without extract and the absorbance in the presence of the sample was denoted by Extract or Standard.

\subsection{ABTS radical scavenging assay}

ABTS (2, 2'-azinobis-3-ethylbenzothiozoline-6-sulphonic acid) assay is based on the scavenging of ABTS radicals. For ABTS assay, the working solution was prepared by mixing equal quantities of 7.4 
$\mathrm{mM}$ ABTS solution and $2.6 \mathrm{mM}$ potassium persulfate solution and allowing them to react for 12 hours at room temperature in the dark. The solution was then diluted by mixing $1 \mathrm{~mL}$ ABTS solution with $60 \mathrm{~mL}$ methanol to obtain an absorbance of 0.7 to 0.8 units at 734 $\mathrm{nm}$ using the spectrophotometer (UV-VIS Shimadzu UV 2450). Fresh ABTS solution was prepared for each assay and used as Blank (Tupe et al. 2013, Re et al. 1999).

Alcoholic and aqueous extracts with different concentrations (200, $300 \& 400 \mu \mathrm{g} / \mathrm{ml}$ ) of Glycyrrhiza glabra were allowed to react with $2.94 \mathrm{ml}$ of the ABTS solution for $6 \mathrm{~min}$ in a dark condition. Trolox (water-soluble analog of vitamin E) in different concentrations $(2.70,4.05,8.10 \& 10.80 \mu \mathrm{g} / \mathrm{ml})$ was used as a standard and the same procedure was used. Then the absorbance was measured at $734 \mathrm{~nm}$ using the spectrophotometer. Results were expressed in $\mathrm{mM}$ Trolox equivalents (TE)/g fresh mass. IC50 value (concentration of sample where absorbance of ABTS decreases $50 \%$ with respect to absorbance of blank) of the sample was determined. Scavenging ability relative to the reaction control (without plant extract) was calculated by using the formula:

ABTS radical scavenging activity $(\%)=\frac{\mathrm{Abs} \text { control }-\mathrm{Abs}_{\text {extract/standard }}}{--------\mathrm{Abs}_{\text {control }}}$

Where Abs control is the absorbance of ABTS radical in Blank \& AbSextract/standard is the absorbance of an ABTS radical solution mixed with extract/ sample.

\subsection{Ferric reducing antioxidant power assay (FRAP)}

The reducing power was determined by the modified Oyaizu method (1986).Substances which have reduction potential react with potassium ferricyanide to form potassium ferrocyanide, which then reacts with ferric chloride to form ferric-ferrous complex that has an absorption maximum at $700 \mathrm{~nm}$.

The different concentrations of sample alcoholic and aqueous extracts $(300,600 \& 900 \mu \mathrm{g} / \mathrm{ml})$ were mixed with $1 \mathrm{ml}$ of sodium phosphate buffer ( $\mathrm{pH} \mathrm{6.6)}$ and $1 \mathrm{ml}$ of $1 \%$ potassium ferricyanide. The mixture was incubated at $50^{\circ} \mathrm{C}$ for $20 \mathrm{~min}$. After that, $1 \mathrm{ml}$ of $10 \%$ trichloroacetic acid (w/v) was added and the mixture was centrifuged at $3000 \mathrm{rpm}$ for $10 \mathrm{~min}$. The upper layer $(1.5 \mathrm{ml})$ was mixed with $1.5 \mathrm{ml}$ deionized water and $0.1 \mathrm{ml}$ of $0.1 \%$ of ferric chloride, kept for $10 \mathrm{~min}$ and the absorbance was measured at $700 \mathrm{~nm}$ by UV-VIS Shimadzu UV 2450 (Hemalatha et al. 2010, Aparadh et al. 2012).The assays were carried out in triplicate and the results are expressed as mean value \pm standard deviation. The extract concentration providing 0.5 of absorbance $\left(\mathrm{EC}_{50}\right)$ was calculated from the graph of absorbance at $700 \mathrm{~nm}$ against extract concentration. Ascorbic acid $(4,8,12,16,20 \mu \mathrm{g} / \mathrm{ml})$ was used as standard.

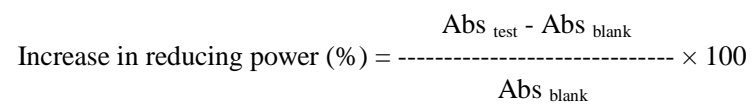

Where Abs test is absorbance of test solution; Abs blank is absorbance of blank. Here reduction of $\mathrm{Fe}\left[(\mathrm{CN})_{6}\right]_{3}$ to $\mathrm{Fe}\left[(\mathrm{CN})_{6}\right]_{2}$ leads to the formation of the intense Perl's Prussian blue complex which gives strong absorbance at $700 \mathrm{~nm}$ with increasing reducing power.

\subsection{Statistical analysis}

The data generated for each mouse were considered for calculation of Mean \pm S.E.M. for different groups. Statistical evaluation of data was done following Students' t-test. A difference was considered significant at $\mathrm{p} \leq 0.05$.

\section{Results}

\subsection{Total flavonoid content (TFC) \& total phenol content (TPC)}

The total flavonoid content (TFC) and total phenol content (TPC) was calculated from the absorbance calibration curve generated with different concentrations of Quercetin and Gallic acid respectively which is shown in Table 1.

Table 1: Estimation of Total Flavonoid Content and Total Phenol Content

\begin{tabular}{lll}
\multicolumn{3}{c}{ Table 1: Estimation of Total Flavonoid Content and Total Phenol Content } \\
\hline Tests (TFC \& TPC) & $\begin{array}{l}\text { Alcoholic Ex- } \\
\text { tract of Glycyr- } \\
\text { rhiza glabra }\end{array}$ & $\begin{array}{l}\text { Aqueous Extract } \\
\text { of Glycyrrhiza } \\
\text { glabra }\end{array}$ \\
\hline $\begin{array}{l}\text { Flavonoid content }(\mu \mathrm{g} \text { Quer- } \\
\text { cetin equivalent } / \mathrm{mg} \text { of ex- } \\
\text { tract) following the standard } \\
\text { curve }\left(\mathrm{R}^{2}=0.979\right)\end{array}$ & 15.03 & 6.62 \\
$\begin{array}{l}\text { Phenol content }(\mu \mathrm{g} \text { Gallic } \\
\text { acid equivalent } / \mathrm{mg} \text { of ex- } \\
\text { tract) following the standard } \\
\text { curve }\left(\mathrm{R}^{2}=0.979\right)\end{array}$ & 18.70 & 23.26 \\
\hline
\end{tabular}

\subsection{Hydrogen peroxide radical scavenging}

The HPS activity has usually been determined by following the rate of $\mathrm{H}_{2} \mathrm{O}_{2}$ consumption in an incubation system $\left(\mathrm{H}_{2} \mathrm{O}_{2}+\right.$ scavenger $)$ using the classical UV-method. The results of the hydrogen peroxide scavenging test of the alcoholic and aqueous extracts of Glycyrrhiza glabra in comparison with the standard (ascorbic acid) at 230 $\mathrm{nm}$ are shown in table 2. The percentage of inhibition against different concentrations of both extracts of the research drug as well as ascorbic acid was used to plot the standard curve which was used to calculate the $\mathrm{IC}_{50}(\mu \mathrm{g} / \mathrm{ml})$ of each sample, which was determined as $65.064 \pm 3.538,73.423 \pm 9.057$ and $18.156 \pm 1.356$ for alcoholic extract, aqueous extract and Ascorbic Acid respectively.

Table 2: Hydrogen Peroxide Scavenging Activity of Extracts of Glycyrrhiza Glabra

\begin{tabular}{llll}
\hline Research Samples & $\begin{array}{l}\text { Concentration } \\
(\mu \mathrm{g} / \mathrm{ml})\end{array}$ & $\begin{array}{l}\text { \% of Inhi- } \\
\text { bition }\end{array}$ & $\begin{array}{l}\mathrm{IC}_{50}(\mu \mathrm{g} / \mathrm{ml}) \\
\text { from standard } \\
\text { curve }\end{array}$ \\
\hline Alcoholic Extract & 24.94 & 20.82 & $65.064 \pm 3.538$ \\
of Glycyrrhiza & 49.75 & 34.09 & $\left(\mathrm{R}^{2}=0.9662\right)$ \\
glabra & 74.44 & 59.95 & \\
Aqueous Extract & 24.94 & 13.19 & $73.423 \pm 9.057$ \\
of Glycyrrhiza & 49.75 & 21.70 & $\left(\mathrm{R}^{2}=0.8895\right)$ \\
glabra & 74.44 & 56.60 & \\
& 12.42 & 19.91 & $18.156 \pm 1.356$ \\
Ascorbic Acid as & 24.69 & 83.41 & $\left.\mathrm{R}^{2}=0.989\right)$ \\
Standard & 36.81 & 132.70 & \\
\hline Vla & 48.78 & 167.77 & \\
\hline
\end{tabular}

Values are represented as Mean \pm SEM

\subsection{DPPH radical scavenging assay}

DPPH has been widely used to evaluate the free-radical scavenging effectiveness of various antioxidant substances. In the DPPH assay, the antioxidants could reduce the stable radical DPPH to the yellowcolored diphenyl-picryl hydrazine at $517 \mathrm{~nm}$. The results are expressed as the $\mathrm{IC}_{50}$ value (the amount of antioxidant necessary to decrease the initial DPPH concentration by $50 \%$ ). The results of the DPPH radical scavenging test of alcoholic and aqueous extracts of Glycyrrhiza glabra in comparison with the standard (ascorbic acid) are shown in table 3 . The percentages of inhibition against different concentrations of both extracts of the research drug as well as ascorbic acid were used to plot the standard curve which was used to calculate the $\mathrm{IC}_{50}(\mu \mathrm{g} / \mathrm{ml})$ of each sample, which was determined as $1.424 \pm 0.013$ in alcoholic extract, $1.632 \pm 0.052$ in aqueous extract of Glycyrrhiza glabra and $0.879 \pm 0.273$ in Ascorbic Acid respectively. 
Table 3: DPPH Radical Scavenging Activity of Extracts of Glycyrrhiza Glabra

\begin{tabular}{llll}
\hline Research Sample & $\begin{array}{l}\text { Concentration } \\
(\mathrm{mg} / \mathrm{ml})\end{array}$ & $\begin{array}{l}\% \text { of Inhi- } \\
\text { bition }\end{array}$ & $\begin{array}{l}\mathrm{IC}_{50}(\mathrm{mg} / \mathrm{ml}) \\
\text { from standard } \\
\text { curve }\end{array}$ \\
\hline $\begin{array}{l}\text { Alcoholic Extract } \\
\text { of Glycyrrhiza }\end{array}$ & 0.500 & 21.08 & $1.424 \pm 0.013$ \\
glabra & 1.000 & 38.07 & $\left(\mathrm{R}^{2}=0.998\right)$ \\
Aqueous Extract & 0.500 & 67.32 & \\
of Glycyrrhiza & 1.000 & 10.13 & $1.632 \pm 0.052$ \\
glabra & 2.000 & 27.94 & $\left(\mathrm{R}^{2}=0.999\right)$ \\
& 0.05 & 60.13 & \\
Ascorbic Acid as & 0.10 & 3.59 & \\
Standard & 0.15 & 9.97 & $0.879 \pm 0.273$ \\
& 0.20 & 10.78 & $\left(\mathrm{R}^{2}=0.999\right)$ \\
\hline
\end{tabular}

Values are represented as Mean \pm SEM

\subsection{ABTS radical scavenging assay}

In this assay, ABTS is converted to its radical cation by addition of sodium persulfate. This radical cation is blue in color and absorbs light at $734 \mathrm{~nm}$. The ABTS radical cation is reactive towards most antioxidants including phenolics, thiols and Vitamin C. During this reaction, the blue ABTS radical cation is converted back to its colorless neutral form. The reaction may be monitored spectrophotometrically. This assay is often referred to as the Trolox equivalent antioxidant capacity (TEAC) assay.

The results of the ABTS radical scavenging test of the alcoholic and aqueous extracts of the herbal rejuvenator drug in comparison with the standard (Trolox) are shown in table 4 . The percentage of inhibition against different concentrations of both extracts of Glycyrrhiza glabra as well as Trolox as Standard was used to plot the standard curve and used to calculate the $\mathrm{IC}_{50}(\mu \mathrm{g} / \mathrm{ml})$ of each sample which was determined as $575 \pm 26.694$ in alcoholic extract, 683.9 \pm 49.220 in aqueous extract of Glycyrrhiza glabra and $6.337 \pm 0.167$ in Trolox respectively. It is also observed that inhibition percentage values go on increasing with increases in concentration of research plant extracts in the assay mixture.

Table 4: Percentage of ABTS Radical Scavenging Activity Using Trolox

\begin{tabular}{|c|c|c|c|}
\hline Research Samples & $\begin{array}{l}\text { Concentration } \\
(\mu \mathrm{g} / \mathrm{ml})\end{array}$ & $\begin{array}{l}\% \text { of Inhi- } \\
\text { bition }\end{array}$ & $\begin{array}{l}\mathrm{IC}_{50}(\mu \mathrm{g} / \mathrm{ml}) \\
\text { from standard } \\
\text { curve }\end{array}$ \\
\hline \multirow{3}{*}{$\begin{array}{l}\text { Alcoholic Extract } \\
\text { of Glycyrrhiza } \\
\text { glabra }\end{array}$} & 200 & 5.56 & \multirow{3}{*}{$\begin{array}{l}575 \pm 26.694 \\
\left(\mathrm{R}^{2}=0.995\right)\end{array}$} \\
\hline & 300 & 16.13 & \\
\hline & 400 & 29.68 & \\
\hline \multirow{4}{*}{$\begin{array}{l}\text { Aqueous Extract } \\
\text { of Glycyrrhiza } \\
\text { glabra }\end{array}$} & 200 & 12.44 & \multirow{4}{*}{$\begin{array}{l}683.9 \pm 49.220 \\
\left(\mathrm{R}^{2}=0.997\right)\end{array}$} \\
\hline & 300 & 20.56 & \\
\hline & 400 & 28.17 & \\
\hline & 2.70 & 22.46 & \\
\hline \multirow{3}{*}{$\begin{array}{l}\text { Trolox as Stand- } \\
\text { ard }\end{array}$} & 4.05 & 32.36 & \multirow{3}{*}{$\begin{array}{l}6.337 \pm 0.167 \\
\left(R^{2}=1\right)\end{array}$} \\
\hline & 8.10 & 63.58 & \\
\hline & 10.8 & 83.88 & \\
\hline
\end{tabular}

$\mathrm{V}$ alues are represented as Mean $+\mathrm{SEM}$

\subsection{Ferric reducing antioxidant power (FRAP) assay}

In this assay the yellow colour of the test solution changes to various shades of green and blue depending upon the reducing power of each compound. The presence of radicals (i.e. antioxidants) causes the conversion of the $\mathrm{Fe}^{3+} /$ ferricyanide complex used in this method to the ferrous form indicated by the formation of pearls Prussian blue at $700 \mathrm{~nm}$.

The results of the Ferric Reducing Power Assay test of the alcoholic and aqueous extracts of Glycyrrhiza glabra in comparison with the standard (ascorbic acid) at $700 \mathrm{~nm}$ is shown in table 5. The percentage of inhibition against different concentrations of both extracts of the research drug as well as ascorbic acid was used to plot the standard curve which was used to calculate the $\mathrm{IC}_{50}(\mu \mathrm{g} / \mathrm{ml})$ of each sample, which was determined as $335.948 \pm 29.040,251.891 \pm 6.330$ and $6.142 \pm 0.061$ for alcoholic extract, aqueous extract of Glycyrrhiza glabra and Ascorbic Acid respectively. It is also observed that inhibition percentage values go on increasing with enhancements in concentration of research plant extracts in the assay mixture.
Table 5: Results of FRAP Essay

\begin{tabular}{|c|c|c|c|}
\hline Research Samples & $\begin{array}{l}\text { Concentration } \\
(\mu \mathrm{g} / \mathrm{ml})\end{array}$ & $\begin{array}{l}\% \text { of Inhi- } \\
\text { bition }\end{array}$ & $\begin{array}{l}\mathrm{IC}_{50}(\mu \mathrm{g} / \mathrm{ml}) \\
\text { from standard } \\
\text { curve }\end{array}$ \\
\hline \multirow{3}{*}{$\begin{array}{l}\text { Alcoholic Extract } \\
\text { of Glycyrrhiza } \\
\text { glabra }\end{array}$} & 600 & 131.95 & 335.948 \\
\hline & 800 & 191.91 & \pm 29.040 \\
\hline & 1000 & 258.46 & $\left(\mathrm{R}^{2}=0.998\right)$ \\
\hline \multirow{4}{*}{$\begin{array}{l}\text { Aqueous Extract } \\
\text { of Glycyrrhiza } \\
\text { glabra }\end{array}$} & 600 & 214.61 & \multirow{4}{*}{$\begin{array}{l}251.891 \pm 6.330 \\
\left(\mathrm{R}^{2}=0.994\right)\end{array}$} \\
\hline & 800 & 294.69 & \\
\hline & 1000 & 398.64 & \\
\hline & 4 & 33.33 & \\
\hline \multirow{4}{*}{$\begin{array}{l}\text { Ascorbic Acid as } \\
\text { Standard }\end{array}$} & 8 & 64.29 & \multirow{4}{*}{$\begin{array}{l}6.142 \pm 0.061 \\
\left(\mathrm{R}^{2}=0.998\right)\end{array}$} \\
\hline & 12 & 133.30 & \\
\hline & 16 & 171.43 & \\
\hline & 20 & 264.28 & \\
\hline
\end{tabular}

Values are represented as Mean \pm SEM

\section{Discussion}

The total phenolic content of the alcoholic root extract was 18.70 Gallic acid equivalents/mg while it was 23.26 for the aqueous extract. Similarly, the total flavonoid content was assessed as 15.03 and 6.62 Quercetin equivalent $/ \mathrm{mg}$ for these two extracts respectively. Thus, the Alcoholic extracts of research drug shows more Quercetin equivalent content indicating higher Flavonoids than its aqueous extract. However, its aqueous extract shows more Gallic acid equivalents (higher Total Phenol Content) than its alcoholic extract. Flavonoids, including flavones, flavanols and condensed tannins, are plant secondary metabolites, the antioxidant activity of which depends on the presence of free $\mathrm{OH}$ groups, especially 3-OH. Plant flavonoids have antioxidant activity in vitro and also act as antioxidants in vivo. Plants rich in secondary metabolites, including phenolics, flavonoids and carotenoids, have antioxidant activity due to their redox properties and chemical structures (Geetha et al. 2003, Shimoi et al. 1996).

Examination of the $\mathrm{IC}_{50}$ values obtained during Hydrogen Peroxide Radical Scavenging test indicates that when compared with the standard drug ascorbic acid, around 3 - 4 times concentrations of the aqueous and alcoholic extracts of the research drug are required for scavenging $50 \%$ Hydrogen peroxides. The free radical scavenging effect in respect of Hydrogen Peroxide was found higher in the alcoholic extract of Glycyrrhiza glabra as compared to its aqueous extract at all observed concentration levels. However, the observed radical scavenging effect at all concentrations for both aqueous and alcoholic extracts of the research drug was quite low in comparison to ascorbic acid.

The high phenolic and flavonoid content is responsible for the bioactivity of these crude extracts. Flavonoids are highly effective scavengers of most oxidizing molecules, including singlet oxygen, and various other free radicals implicated in several diseases. Hydrogen peroxide $\left(\mathrm{H}_{2} \mathrm{O}_{2}\right)$, a biologically relevant, non-radical oxidizing species, may be formed in tissues through oxidative processes, but there has been limited information regarding its scavenging by polyphenolic antioxidants. Among reactive oxygen species (ROS), hydrogen peroxide $\left(\mathrm{H}_{2} \mathrm{O}_{2}\right)$ is a relatively stable, non-radical oxidant, which can diffuse across biological membranes. It is produced by 2-electron reduction of molecular oxygen or by dismutation of the superoxide anion radical (Shukla et al. 2009, Bravo 1998, Agati et al. 2012).

The 2, 2-diphenylpicrylhydrazyl (DPPH) assay is widely used in plant biochemistry to evaluate the properties of plant constituents for scavenging free radicals. The method is based on the spectrophotometric measurement of the DPPH concentration change resulting from the reaction with an antioxidant. Ascorbic acid or Vitamin $C$ has been used as the standard in this research since it is a water-soluble free radical scavenger. Moreover, it regenerates vitamin $\mathrm{E}$ in cell membranes in combination with compounds capable of donating reducing equivalents. Vitamin $\mathrm{C}$ changes to the ascorbate radical by donating an electron to the lipid radical in order to terminate the lipid peroxidation chain reaction (Nimse \& Pal 2015).It is noticed that aqueous and alcoholic extracts of the research drug are required in higher concentrations than the ascorbic 
acid standard for performing antioxidant activity measured by assessing the concentration required for $50 \%$ scavenging of the DPPH radical, i.e. $\mathrm{IC}_{50}(\mu \mathrm{g} / \mathrm{ml})$. The alcohol extracts having higher flavonoids exhibits higher scavenging activity during the DPPH essay test as compared to the aqueous extract. The free-radical scavenging effect assessed as percentage inhibition was found to be 38.07 in the alcoholic extract of Glycyrrhiza glabra at $1.0 \mathrm{mg} / \mathrm{ml}$ concentration as compared to 27.94 at same concentration in the aqueous extract. It is also observed that inhibition percentage increases commensurate with increases in concentration of research plant extracts in the assay mixture during DPPH test.

An antioxidant has the ability to donate a hydrogen atom that will quench the stable free radical which is associated with a change in absorption, which can be followed calorimetrically. The pre-formed radical mono-action of $\left(\mathrm{ABTS}^{\cdot+}\right)$ is generated by oxidation of ABTS with potassium per-sulfate and is reduced in the presence of hydrogen-donating antioxidants. The influences of both the concentration of antioxidant and duration of reaction are taken into account when determining the antioxidant activity. It is observed that for any particular level of antioxidant activity, higher concentrations of aqueous and alcoholic extracts of Glycyrrhiza glabra are required than the standard ascorbic acid. This phenomenon is clearly observed when measuring the antioxidant activity for scavenging $50 \%$ ABTS radicals as evaluated in the form of $\mathrm{IC}_{50}(\mu \mathrm{g} / \mathrm{ml})$. The freeradical scavenging effect measured as percentage inhibition in case of the stable ABTS was found to be 28.17 in the aqueous extract at $400 \mu \mathrm{g} / \mathrm{ml}$ concentration as compared to 29.68 in alcoholic extract at the same concentration of Glycyrrhiza glabra, indicating higher antioxidant capacity in the alcoholic extract as compared to the aqueous extract. The standard drug Trolox showed high inhibition at very low values of concentration in comparison to both the aqueous and alcoholic extracts. Since Trolox is a water-soluble analog of vitamin $\mathrm{E}$, it is used as an antioxidant like vitamin $\mathrm{E}$ in biological or biochemical applications to reduce oxidative stress or damage.

FRAP is an electron transfer based total antioxidant assay, also called redox linked colorimetric method. There is an increase in absorbance at a pre-specified wavelength as an antioxidant reacts with chromogenic reagent (Fe (II)) (Everest \& Ozturk 2005). The percentage of inhibition at $600 \mu \mathrm{g} / \mathrm{ml}$ concentration of Glycyrrhiza glabra was found to be 131.95 in case of alcoholic and 214. 61for aqueous extract, while it was $191.91 \%$ and $294.69 \%$ in case of alcoholic and aqueous extracts respectively at $800 \mu \mathrm{g} / \mathrm{ml}$ concentration. Thus, the aqueous extract of the research drug consistently showed higher inhibition and, therefore, higher antioxidant activity during this study. The percentage inhibition as well as the $\mathrm{IC}_{50}$ values clearly indicates that the standard (ascorbic acid) showed very low $\mathrm{IC}_{50}$ levels indicating its very high antioxidant capacity in comparison with both the alcoholic and aqueous extracts of Glycyrrhiza glabra during this test.

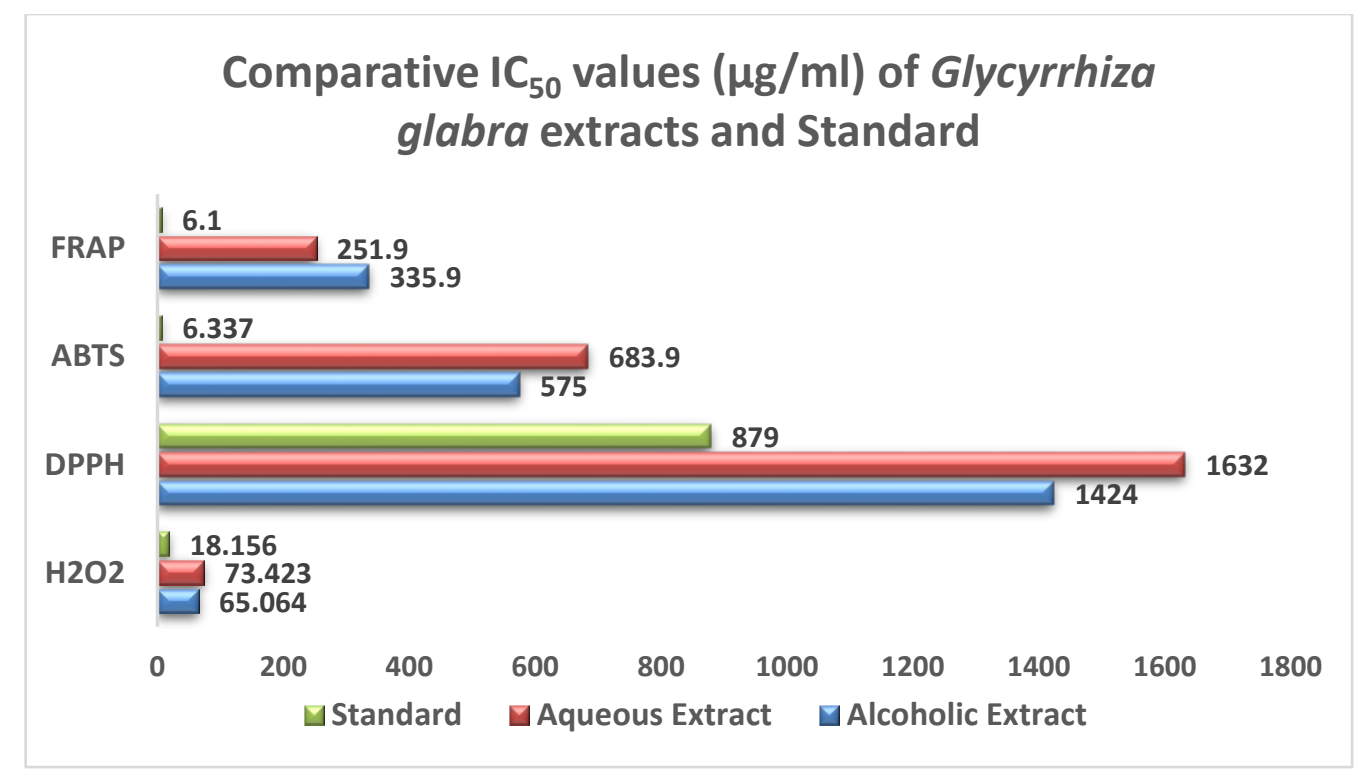

Fig. 1: Comparative $\mathrm{IC}_{50}$ Values of Glycyrrhiza Glabra Extracts and Standard Drug.

The obtained $\mathrm{IC}_{50}$ values in respect of the two extracts of Glycyrrhiza glabra as well as the standard drug using the various techniques discussed above have been shown in fig. 1. It is evident from these findings that aqueous extract shows higher level of antioxidant activity as compared to the alcoholic extract in all the methods of analysis.

\section{Conclusion}

The evaluation of in vitro antioxidant activity of the aqueous and alcoholic extracts of Glycyrrhiza glabra showed substantial and significant free radical scavenging activity during the study in both the extracts which is comparable to that of the standard drug, especially in Hydrogen Peroxide and DPPH essays. The alcoholic extract exhibits a higher level of activity than the aqueous extract in all the antioxidant assessment techniques except FRAP. This significant pronounced antioxidant activity of alcoholic extracts may be due to the presence of higher concentrations of flavonoids in it as compared to the aqueous extract. This in vitro assessment of the antioxidant properties of the aqueous and alcoholic extracts of Glycyr- rhiza glabra validates and confirms its free-radical scavenging activity as described in the ancient texts of Ayurvedic system of Medicine.

\section{Conflict of interests}

The authors declare that there is no conflict of interests regarding the publication of this paper.

\section{Acknowledgements}

This research work was supported by grants from the Department of Science and Technology, Government of West Bengal, and we are grateful for that. We are thankful to Dr. A.K. Mandal, superintendent, Institute of Post Graduate Ayurvedic Education and Research, Kolkata for providing necessary help during the experimental work. 


\section{References}

[1] Agati G, Azzarello E, Pollastri S\& Tattini M 2012, Flavonoids as antioxidants in plants: location and functional significance. Plant Sci 196, 67-76. http://dx.doi.org/10.1016/i.plantsci.2012.07.014

[2] Anil KV, Babul D\& Rama T 2011, Evaluation of Anti-ulcerogenic properties from the root of Flemingia strobilifera. Journal of Basic and Clinical Pharmacy 2 (1), 33-39.

[3] Aparadh VT, Naik VV\&Karadge BA 2012, Antioxidative Properties (TPC, DPPH, FRAP, Metal Chelating Ability, Reducing Power and TAC) within some Cleome Species. Ann. Bot. (Roma) 2, 49-56.

[4] Baba SA \&Malik SA 2015, Determination of total phenolic and flavonoid content, antimicrobial and antioxidant activity of a root extract of Arisaema jacquemontii. Journal of Taibah University for Science 9, 449-454. http://dx.doi.org/10.1016/i.jtusci.2014.11.001.

[5] Basniwal PK, Suthar M, Rathore GS, Gupta R, Kumar V, Pareek A \& Jain D 2009, In-vitro antioxidant activity of hot aqueous extract of Helicteres isora Linn. fruits. Natural Product Radiance 8 (5), 483-87.

[6] Bravo L 1998, Polyphenols: chemistry, dietary sources, metabolism and nutritional significance. Nutr. Rev 56, 317-333. http://dx.doi.org/10.1111/j.1753-4887.1998.tb01670.x.

[7] Chang C, Yang M, Wen H\& Chern J 2002, Estimation of total flavonoid content in propolis by two complementary colorimetric methods. J. Food Drug Anal 10, 178-182.

[8] Everest A \& Ozturk E 2005, Focusing on the ethnobotanical uses of plants in Mersin and Adana provinces (Turkey). Journal of Ethnobiology and Ethnomedicine1 (6). http://dx.doi.org/10.1186/1746 4269-1-6.

[9] Geetha S, Sai-Ram M, Mongia SS, Singh V \& Ilavazhagan G 2003 , Evaluation of antioxidant activity of leaf extract of sea buckthorn (Hippophae rhamnoides L.) on chromium (VI) induced oxidative stress in albino rats. J. Ethnopharmacol 87, 247-251. http://dx.doi.org/10.1016/S0378-8741(03)00154-5.

[10] Harborne JB 1984, Phytochemical Methods: A guide to Modern Technique of Plant Analysis, $2^{\text {nd }}$ edition, Chapmann and Hall: London. http://dx.doi.org/10.1007/978-94-009-5570-7.

[11] Hemalatha S, Lalitha P\& Arulpriya P 2010, Anti-oxidant activities of the extracts of the aerial roots of Pothos aurea (Linden ex Andre). Der. Pharma. Chemica 2 (6), 84-89.

[12] Keser S, Celik S, Turkoglu S, Yilmaz O \& Turkoglu I 2012, Hydrogen Peroxide Radical Scavenging and Total Antioxidant Activity of Hawthorn. Chemistry Journal 02 (1), 9-12.

[13] Kirtikar KR \& Basu BD 1989, Indian Medicinal Plants, vol. 2, Allahabad, pp. 312-313.

[14] Nimse SB\& Pal DK 2015, Free radicals, natural antioxidants, and their reaction mechanisms, (Review Article) RSC Adv5, 2798628006. http://dx.doi.org/10.1039/C4RA13315C.

[15] Nishaa S, Vishnupriya M, Sasikumar JM, Hephzibah PC \& Gopalakrishnan VK 2012, Antioxidant activity of ethanolic extract of Maranta arundinacea L. tuberous rhizomes. Asian Journal of Pharmaceutical and Clinical Research 5 (4), 85-88.

[16] Oyaizu M 1986, Studies on product of browning reaction prepared from glucose amine. Jpn. J. Nutr 44, 307-315 http://dx.doi.org/10.5264/eiyogakuzashi.44.307.

[17] Özcelik B, Lee JH\& Min DB 2003, Effects of light, oxygen and pH on the 2, 2-diphenyl-1-picrylhydrazyl (DPPH) method to evaluate antioxidants. J. Food Sci 68, 487-490. http://dx.doi.org/10.1111/j.1365-2621.2003.tb05699.x.

[18] Re R, Pellegrini N, Proteggente A, Pannala A, Yang M\& Rice-Evans C 1999, Antioxidant activity applying an improved ABTS radical cation decolourization assay. Free Radic. Biol. Med 26, 1231-1237. http://dx.doi.org/10.1016/S0891-5849(98)00315-3.

[19] Sharma PC, Yelne MB\& Dennis TJ 2001, Database on medicinal plants used in Ayurveda, vol. 8, Central Council for Research in Ayurveda \& Siddha, Department of Indian system of medicine, Govt. of India, New Delhi, pp. 42 -58.

[20] Sharma PV 1995, Introduction to Dravyaguna (Indian Pharmacology), vol. 2, Chaukhamba Orientalia: Varanasi, India, pp. 734-736.

[21] Shimoi K, Masuda S, Shen B, Furugori M\& Kinze N 1996, Radioprotective effects of antioxidative plant flavonoids in mice. Mutat Res. Fund. Mol 350, 153-161. http://dx.doi.org/10.1016/00275107(95)00116-6.

[22] Shukla S, Mehta A, Bajpai KV\& Shukla S 2009, In vitro antioxidan activity and total phenolic content of ethanolic leaf extract of Stevia rebaudiana Bert. Food Chem. Toxicol 47, 2338-2343. http://dx.doi.org/10.1016/j.fct.2009.06.024.

[23] Tupe RS, Kemse NG\& Khaire AA 2013, Evaluation of Antioxidan potentials and Total Phenolic contents of Selected Indian Herbs powder extracts. Indian Food Research journal 20 (3), 1053-63.
[24] Usha Sri B, Ibrahim M\& Mahendra Kumar CB 2012, Antioxidant activity and total flavonoids content of different parts of Azadirachta indica A. Juss. Journal of Medicinal Plants Research 6 (46), 5737 5742.

[25] Wang SY\& Jiao H2000, Scavenging capacity of berry crops on superoxide radicals, hydrogen peroxide, hydroxyl radicals, and singlet oxygen. J. Agric. Food. Chem 48 (11), 5677-84 http://dx.doi.org/10.1021/jf000766i.

[26] Živković J, Zeković Z, Mujić I, Vidović S, Cvetković D, Lepojević Ž, Nikolić G\&Trutić N 2010, Scavenging Capacity of Superoxide Radical and Screening of Antimicrobial Activity of Castanea sativa Mill. Extracts. Czech. J. Food. Sci 28 (1), 61-68. 